\title{
Dissemination of Extended-Spectrum $\beta$-Lactamases and Quinolone Resistance Genes Among Clinical Isolates of Uropathogenic Escherichia coli in Children
}

\author{
Iraj Sedighi ${ }^{1}$; Mohammad Reza Arabestani ${ }^{2,3}$; Ali Rahimbakhsh ${ }^{4}$; Zahra Karimitabar ${ }^{2}$; \\ Mohammad Yousef Alikhani ${ }^{2,3,}$ \\ ${ }_{2}^{1}$ Department of Pediatric, Faculty of Medicine, Hamadan University of Medical Sciences, Hamadan, IR Iran \\ ${ }^{2}$ Department of Microbiology, Faculty of Medicine, Hamadan University of Medical Sciences, Hamadan, IR Iran \\ ${ }^{3}$ Brucellosis Research Center, Hamadan University of Medical Sciences, Hamadan, IR Iran \\ ${ }^{4}$ Department of Microbiology, Faculty of Basic and Medical Sciences, Islamic Azad University of Zanjan, Zanjan, IR Iran \\ ${ }^{*}$ Corresponding author: Mohammad Yousef Alikhani, Brucellosis Research Center, Hamadan University of Medical Sciences, Hamadan, IR Iran. Tel: +98-8118380755, Fax: +98- \\ 8118380130, E-mail: alikhani@umsha.ac.ir
}

Received: March 30, 2014; Revised: July 23, 2014; Accepted: July 26, 2014

\begin{abstract}
Background: Urinary tract infection (UTI) is one of the most common childhood bacterial infections and Escherichia coli is the major pathogen. Producing $\beta$-lactamase enzymes are the most common mechanism of bacterial resistance.

Objectives: This study aimed to determine the prevalence of Extended-Spectrum $\beta$-Lactamases (ESBLs) and Quinolone Resistance (qnr) genes in E. coli strains isolated from UTIs.

Materials and Methods: In this study, a total of 120 isolates of E. coli from urinary tract infections of the children were collected at Besat Hospital in Hamadan, Iran, from October 2010 to October 2011. The bacterial isolates were identified by standard biochemical methods. Antimicrobial susceptibilities were determined by disk diffusion method, and ESBLs-producing was confirmed phenotypically using the double-disk synergy (DDS) test. The presence and identification of ESBLs and qnr genes were determined by Polymerase Chain Reaction (PCR).

Results: The highest sensitivity was seen to imipenem (96.7\%), amikacin (92.5\%), nitrofurantoin (93.3\%), ofloxacin (81.7\%), gentamicin norfloxacin (70.8\%), and ciprofloxacin (79.2\%). In contrast, the highest rate of resistance was seen to co-trimoxazole (77\%) and nalidixic acid (40.9\%). The results showed that 6 (2.18\%) and 4 (1.12\%) isolates of ESBL-producing E. coli were positive with respect to having qnrB and qnrS genes, respectively. No isolates was found to have qnrA.

Conclusions: CTX-M was the most prevalentESBL genotype in uropathogenic E. coli (UPEC) isolated from UTI. In addition, a high frequency of qnr genes among ESBL-producing E. coli was identified in this study. In order to avoid treatment failures, we recommend using phenotypic and molecular methods to diagnose these enzymes and qnr genes.
\end{abstract}

Keywords: Quinolones; Antibiotic Resistance; Escherichia coli

\section{Background}

Urinary tract infection (UTI) is one of the most common childhood bacterial infections and also the second common infection among different societies. It is also an important factor in creating scar and progressive destruction of renal structure, chronic renal failure, poor growth, urinary stones, and hypertension in children (1). Escherichia coli is the most important opportunistic pathogen causing more than $80 \%$ of urinary tract infections (2). $\beta$-Lactam antibiotics have been widely used to treat E. coli infections; however, treatment of UTIs has become increasingly problematic. The incidence rate of antibiotic resistance towards these antibiotics is growing every day in the world (3). Producing $\beta$-lactamase enzymes are the most common mechanism of bacterial resistance. Extended-spectrum $\beta$-lactamases (ESBLs)producing bacteria have usually multi-drug resistance, because most of the times, the genes related to the other resistive mechanisms have been also placed on the same plasmid carrying the genes encoding ESBLs (4-6).

Fluoroquinolones are wide spectrum potent drugs, used in treating a wide range of infections. Although fluoroquinolones are not approved for use in persons under 18 years of age, with increasing resistance to cephalosporins, they can be used in critically ill patients with Gram-negative infections and in children with complicated urinary tract infections (7). Their extensive use has been associated with raising level of quinolone resistance. The principle mechanism of quinolone resistance was attributed to the chromosomal mutations in DNA gyrase, DNA topoisomerase IV, or active efflux pumps. However, a plasmid-mediated quinolone resistance gene encoding a pentapeptide repeat protein (qnr) was discovered in 1998 (8).

Copyright (C) 2015, Ahvaz Jundishapur University of Medical Sciences. This is an open-access article distributed under the terms of the Creative Commons Attribution-NonCommercial 4.0 International License (http://creativecommons.org/licenses/by-nc/4.0/) which permits copy and redistribute the material just in noncommercial usages, provided the original work is properly cited. 
A range of plasmid-mediated quinolone resistance determinants, including $q n r$, have been reported global in clinical isolates of Enterobacteriaceae $(9,10)$. These $q n r$ genes are frequently associated with ESBLs (9). Various studies around the world have shown that the releasing $q n r$ genes are among the bacterial isolates. Gene qnrA causes quinolone resistance and Minimum inhibitory concentration (MIC) increases the fluoroquinolones up to 32 times in E. coli. This gene has been reported from all over the world. The other qnrB and qnrS plasmid resistance genes are also detected in Enterobacteriaceae, which have the amino acid sequence similarity of $41 \%$ and $60 \%$ with qnrA (10-12). Resistance of Gram-negative bacteria to the extended-spectrum $\beta$-lactam antibiotics has expanded rapidly in last two decades. This resistance is largely attributed to the plasmids, containing genes encoding ESBLs. Since the quinolone resistance genes are also located on plasmid.

\section{Objectives}

We studied the prevalence of ESBLs and frequency of $q n r A, q n r B$, and qnrS genes in E. coli strains isolated from UTIs in children.

\section{Materials and Methods}

This cross-sectional descriptive-analytic study was done on 120 urine samples collected from children suffering from UTI at Besat hospital (children's ward), Hamadan, Iran from October 2010 to October 2011. Midstream urine collection method was performed for toilet-trained children and catheter or suprapubic aspiration was used for non-toilet-trained children. Conventional biochemical tests were used for bacterial identification. The ethics committee of the Hamadan University of Medical Sciences approved the study protocol (No.: 891224115). Inclusion criteria were children younger than 12 years suspected to UTI at Besat hospital and the exclusion criteria were as follows: 1) the patients who had received antibiotic before doing urine sample, 2) The patients that in their urine culture, more than one type of microorganism had grown and sampling was done by urine bag.

\subsection{Antimicrobial Susceptibility}

Antimicrobial susceptibilities were determined by disk diffusion agar assay (13) to co-trimoxazole (25 $\mu \mathrm{g})$, amikacin $(30 \mu \mathrm{g})$, gentamicin $(10 \mu \mathrm{g})$, ceftriaxone $(30 \mu \mathrm{g})$, nalidixic acid $(30 \mu \mathrm{g})$, norfloxacin $(10 \mu \mathrm{g})$, ofloxacin $(5 \mu \mathrm{g})$, ciprofloxacin $(5 \mu \mathrm{g})$, cefixime $(5 \mu \mathrm{g})$, cefotaxime $(30 \mu \mathrm{g})$, ceftazidime (30 $\mu \mathrm{g})$, cefpodoxime (10 $\mu \mathrm{g})$, azteroname (30 $\mu \mathrm{g})$, nitrofurantoin $(300 \mu \mathrm{g})$, and imipenem $(10 \mu \mathrm{g})$ (India HIMEDIA company). The results were interpreted according to the Clinical and Laboratory Standards Institute (CLSI) recommendations (14). The quality control of the study was done by E. coli ATCC 25192.

\subsection{Determination of Extended-Spectrum $\beta$-Lactamases-Producing Strains by the Combined Disk Method}

In order to identify ESBL-producing strains, the double-disk synergy (DDS) test was carried out on MuellerHinton agar (Himedia CO, India) with disks, containing ceftazidime (30 $\mu \mathrm{g})$, cefotaxime (30 $\mu \mathrm{g})$, cefpodoxime (30 $\mu \mathrm{g})$, and ceftriaxone $(30 \mu \mathrm{g})$ placed respectively on the $\mathrm{MH}$ agar to a distance of $20 \mathrm{~mm}$ from combined disks of ceftazidime/clavulanic acid $(30.10 \mu \mathrm{g})$, cefotaxime/clavulanic acid (30.10 $\mu \mathrm{g})$, cefpodoxime/clavulanic acid (30.10 $\mu \mathrm{g})$, and ceftriaxone/clavulanic acid $(30.10 \mu \mathrm{g})$. The zone diameters were read using the CLSI assay. A difference of $\geq 5 \mathrm{~mm}$ between the inhibition zone diameters of either of the cephalosporin disks and their respected cephalosporin-clavulanate disk is considered to be phenotypic confirmation of ESBLs production (14).

\subsection{DNA Extraction}

DNA of ESBL or non-ESBL -producing or quinolone-resistant strains of E. coli was extracted by boiling method as per the guidelines (15). PCR amplification of bla genes, including bla-CTX-M, bla-SHV, bla-TEM, and qnr genes ( $q n r A$, $q n r B, q n r S)$ were performed with the specific primers (16, 17) listed in Table 1. ESBL-positive and ESBL-negative isolates were screened by multiplex PCR for $q n r$ genes. PCR products were analyzed by electrophoresis in a $1.5 \%$ agarose gel, containing SYBR safety at $100 \mathrm{~V}$ for $30 \mathrm{~min}$.

\begin{tabular}{|c|c|c|c|}
\hline Target & Primer Sequence('3 $\rightarrow$ ' 5 ) & Size, bp & References \\
\hline \multirow[t]{2}{*}{ bla-CTX-M } & TCTTCCAGAATAAGGAATCCC & \multirow[t]{2}{*}{909} & \multirow[t]{2}{*}{ (17) } \\
\hline & CCGTTTCCGCTATTACAAAC & & \\
\hline \multirow[t]{2}{*}{ Bla-SHV } & CTTTACTCGCTTTATCG & \multirow[t]{2}{*}{868} & \multirow[t]{2}{*}{ (17) } \\
\hline & TCCCGCAGATAAATCAC & & \\
\hline \multirow[t]{2}{*}{ bla-TEM } & ATGAGTATTCAACATTTCCG & \multirow[t]{2}{*}{931} & \multirow[t]{2}{*}{ (17) } \\
\hline & CCAATGCTTAATCAGTGAGC & & \\
\hline \multirow[t]{2}{*}{ qnrA } & AGAGGATTTCTCACGCCAGG & \multirow[t]{2}{*}{580} & \multirow[t]{2}{*}{ (18) } \\
\hline & TGCCAGGCACAGATCTTGAC & & \\
\hline \multirow[t]{2}{*}{$q n r B$} & GGMATHGAAATTCGCCACTG & \multirow[t]{2}{*}{264} & \multirow[t]{2}{*}{ (18) } \\
\hline & TTTGCYGYYCGCCAGTCGAA & & \\
\hline \multirow[t]{2}{*}{ qnrS } & GCAAGTTCATTGAACAGGGT & \multirow[t]{2}{*}{428} & \multirow[t]{2}{*}{ (18) } \\
\hline & TCTAAACCGTCGAGTTCGGCG & & \\
\hline
\end{tabular}




\subsection{Data Analysis}

Data analyzed by SPSS v.16 using McNemar and Chisquare tests. $P \leq 0.05$ is regarded as significant at $95 \%$ confidence interval.

\section{Results}

Susceptibility testing: In this study, 120 strains of Uropathogenic E. coli (UPEC) isolated from the urine samples of children with UTIs were studied. Of 120 isolates, 25\% ( $\mathrm{n}=$ $30)$ were sensitive to co-trimoxazole, $92.5 \%(n=111)$ to amikacin, $62.5 \%(n=75)$ to ceftriaxone, and 50.8\% $(n=61)$ to nalidixic acid (Table 2). The results demonstrate that 41 strains (34.2\%) were resistant to three or more antibiotics and are known as the strains with multidrug resistance (MDR).

\subsection{Prevalence ofExtended-Spectrum $\beta$-Lactamases in Urinary E. coli Isolates}

The Double-disk synergy test (DDST) detected ESBLs in $33(27.3 \%)$ of isolates which means 87 (71.9\%) were nonESBLs E. coli isolates. For comparison of resistance prevalence to quinolones in ESBL-producing E. coli strains and ESBL-nonproducing strains, intermediate resistance rate of isolates were considered as resistance (Table 3).
Statistical analysis of the results revealed that there is a significant relation between resistance to ciprofloxacin and nalidixic acid in ESBL producing isolates $(\mathrm{P}<0.05)$. However, the prevalence rate of resistance to ofloxacin and norfloxacin in strains of ESBL-producing was more than the strains of non-producing ESBLs. After doing statistical analysis the significant relation was not confirmed.

\subsection{Detection of $\beta$-Lactamase and qnr genes by Polymerase Chain Reaction}

A total of 120 UPEC were tested for bla-CTX-M, bla-SHV, and bla-TEM genes. Our results showed that $66.7 \%(\mathrm{n}=80)$, $20.8 \%(n=25)$, and $40.8 \%(n=49)$ of E. coli isolates harboring bla-CTX-M, bla-SHV, and bla-TEM, respectively (Table 4). Among the investigated E. coli isolates, $11.7 \%$ (14 out of 120) contained qnr genes, of which, $q n r B(\mathrm{n}=8,57.1 \%)$ and $q n r S$ ( $n=6,42.9 \%$ ) were detected. The qnrA gene was not found in any strains. The distribution of qnr containing isolates in ESBL-producing and quinolone-resistant strains are shown in Table 5. Based on the statistical analysis about strains resistant to quinolones, the results of Chi-squared and TauKendal tests proved the existence of a significant relation between the quinolone resistance and presence of qnr genes $(\mathrm{P}<0.05)$.

Table 2. Frequency Distribution of Resistance and Antibiotic Sensitivity in Strains of Uropathogenic E. coli ${ }^{\text {a }}$

\begin{tabular}{lccc}
\hline Antibiotic & Resistance & Intermediate & Sensitive \\
\hline Cefixime & $41(34.2)$ & $5(4.2)$ & $74(61.6)$ \\
Ceftazidime & $42(35)$ & $8(6.7)$ & $70(58.3)$ \\
Cefotaxime & $43(35.8)$ & $7(5.8)$ & $70(58.3)$ \\
Ceftriaxone & $39(32.5)$ & $6(5)$ & $75(62.5)$ \\
Cefpodoxime & $37(30.8)$ & $11(9.2)$ & $72(60)$ \\
\hline Imipenem & $3(2.5)$ & $1(0.8)$ & $116(96.7)$ \\
\hline Azteroname & $40(33.3)$ & $12(10)$ & $68(56.7)$ \\
Gentamicin & $21(17.5)$ & $2(1.7)$ & $97(80.8)$ \\
Amikacin & $7(5.8)$ & $2(1.7)$ & $111(92.5)$ \\
Co-trimoxazole & $85(70.8)$ & $5(4.2)$ & $30(25)$ \\
Nalidixic acid & $49(40.9)$ & $10(8.3)$ & $61(50.8)$ \\
Nitrofurantoin & $0(0)$ & $8(6.7)$ & $112(93.3)$ \\
Ciprofloxacin & $(15) 18$ & $(5.8) 7$ & $(.279) 95$ \\
Norfloxacin & $18(15)$ & $5(4.2)$ & $97(80.8)$ \\
Ofloxacin & $17(14.2)$ & $5(4.2)$ & $98(81.7)$ \\
\hline D & & & \\
\hline
\end{tabular}

a Data are presented as No. (\%).

Table 3. Comparison of Resistance to Quinolones in Extended-Spectrum $\beta$-Lactamases-Producing and Non- Extended-Spectrum $\beta$-Lactamases-Producing E. coli strains ${ }^{\text {a }}$

\begin{tabular}{lcccccccc}
\hline Isolates & \multicolumn{7}{c}{ Quinolones } \\
\cline { 2 - 9 } & \multicolumn{2}{c}{ Ciprofloxacin (CF) } & \multicolumn{1}{c}{ Ofloxacin (OF) } & \multicolumn{2}{c}{ Nalidixic Acid (NA) } & \multicolumn{2}{c}{ Norfloxacin (NX) } \\
\cline { 2 - 9 } & $\mathbf{S}$ & $\mathbf{R}$ & $\mathbf{S}$ & $\mathbf{R}$ & $\mathbf{S}$ & $\mathbf{R}$ & $\mathbf{S}$ & $\mathbf{R}$ \\
\hline ESBL-producing & $19(57.6)$ & $14(42.4)$ & $19(57.6)$ & $14(42.4)$ & $16(48.5)$ & $17(51.5)$ & $20(60.6)$ & $13(39.4)$ \\
Non-ESBL-producing & $76(87.4)$ & $11(12.6)$ & $79(90.8)$ & $8(9.2)$ & $63(72.4)$ & $24(27.6)$ & $77(88.5)$ & $10(11.5)$ \\
\hline a Data are presented as No.(\%). & & & & & &
\end{tabular}




\section{Discussion}

Urinary tract infection is one of the most common childhood infections. The prevalence of UTIs in childhood is $3 \%-5 \%$ (1). There are various studies about the E. coli antibiotic resistance in different parts of the world. For example, Datta et al. stated that the rates of resistance on 87 isolates of $E$. coli to ampicillin, amikacin, cephalexin, ceftazidime, cefotaxime, ceftriaxone, co-trimoxazole, gentamicin, ofloxacin, and ciprofloxacin were 95\%, 41\%, 94\%, 78\%, 87\%, 87\%, 94\%, 64\%, 93\%, and $16 \%$, respectively (18). The spread of ESBL-producing bacteria has been strikingly rapid worldwide, indicating that continuous monitoring system and effective infection control measures are absolutely necessary. In this study, the prevalence of ESBL-producing E. coli by DDST method is $27.3 \%$; whereas in 2003 , this rate was reported at $28.1 \%$ in Lebanon, which is very close to the results of this study (19). Shayanfar et al. (20) in Tehran reported that $28.6 \%$ of $E$. coli isolates are ESBL-producing, which is very close to the result of our study (27.3\%). Different and disturbing rates have been presented from different places of the world. For example, in a hospital in Poland the rate of ESBL-producing was reported at 92.2\% (21) and in some hospitals in Turkey and Spain was $69.14 \%$ and $98.4 \%(22,23)$ respectively. In hospitals of Korea in 2005 this rate was equal to $84.3 \%$ (24). The reason of differences can be due to prolonged staying of the patients in hospital (21), inappropriate and excessive use of antibiotics (22), duration of hospitalization, invasive diagnostic or therapeutic procedures, type of cephalosporins, and test method.

In the present research, our statistics suggest that CTX-M (66.7\%) could be the most prevalent, followed by bla-TEM (40.8\%) and bla-SHV (20.8\%). In Pakistan, the frequency of CTX-M gene was reported at 100\% (25) and in 2011, Yazdi et al. reported it at $87.1 \%$ (26). The rate of bla-TEM gene in Belgium was reported at 44\% (27) and in 2009 in France it was $52.9 \%$ (28), which was close to our statistics. The frequency of bla-SHV is higher compared with the results of the studies done by Jonas Bonnedahl et al. in France as $11.7 \%$ (28) or Hussain et al. in Pakistan as 15.4\% (25). In 2011, Yazdi et al. reported the frequency of this gene as $70.6 \%$ (26) and in 2008 in Brazil it was equal to $67.8 \%$, which is higher than its frequency in our area.

Table 4. Molecular Features of $\beta$-Lactamase Genes in strains of $\operatorname{UPEC}(\mathrm{n}=120)^{\mathrm{a}}$

\begin{tabular}{lc}
\hline Genotype & Isolates \\
\hline CTX-M.TEM.SHV & $13(10.8)$ \\
\hline CTX-M.TEM & $25(20.8)$ \\
\hline CTX-M.SHV & $8(6.7)$ \\
TEM.SHV & $2(1.7)$ \\
CTX-M & $34(28.3)$ \\
TEM & $9(7.5)$ \\
SHV & $2(1.7)$ \\
\hline
\end{tabular}

a Data are presented as No.(\%).

\begin{tabular}{|c|c|c|c|c|c|c|c|c|c|}
\hline \multirow[t]{2}{*}{ Isolates Number } & \multirow[t]{2}{*}{ ESBL Producing } & \multirow[t]{2}{*}{ Quinolone-Resistant } & \multicolumn{4}{|c|}{ Status of Quinolone-Resistant } & \multirow[t]{2}{*}{$q n r A$} & \multirow[t]{2}{*}{$q n r B$} & \multirow[t]{2}{*}{ qnrs } \\
\hline & & & $\mathbf{C F}$ & OF & NA & NX & & & \\
\hline 1 & $++^{a}$ & & S & $S$ & $S$ & S & & & + \\
\hline 2 & + & & $S$ & $S$ & $S$ & $S$ & & + & \\
\hline 3 & + & + & $S$ & $S$ & $\mathrm{R}$ & $S$ & & + & \\
\hline 4 & + & + & $\mathrm{R}$ & $\mathrm{R}$ & $\mathrm{R}$ & $\mathrm{R}$ & & & + \\
\hline 5 & + & + & $\mathrm{R}$ & $\mathrm{R}$ & $\mathrm{R}$ & $\mathrm{R}$ & & & + \\
\hline 6 & + & + & $\mathrm{R}$ & $\mathrm{R}$ & $\mathrm{R}$ & $\mathrm{R}$ & & + & \\
\hline 7 & + & + & $\mathrm{R}$ & $\mathrm{R}$ & $\mathrm{R}$ & $\mathrm{R}$ & & + & \\
\hline 8 & + & + & S & $\mathrm{S}$ & $\mathrm{R}$ & $S$ & & + & \\
\hline 9 & + & + & $\mathrm{R}$ & $\mathrm{R}$ & $\mathrm{R}$ & $\mathrm{R}$ & & & + \\
\hline 10 & + & + & $\mathrm{R}$ & $\mathrm{R}$ & $\mathrm{R}$ & $\mathrm{R}$ & & + & \\
\hline 11 & & + & $\mathrm{R}$ & $\mathrm{R}$ & $\mathrm{R}$ & $\mathrm{R}$ & & + & \\
\hline 12 & & + & $\mathrm{R}$ & $\mathrm{R}$ & $\mathrm{R}$ & $\mathrm{R}$ & & & + \\
\hline 13 & & + & $S$ & $\mathrm{R}$ & $S$ & $S$ & & & + \\
\hline 14 & & + & $S$ & $S$ & $\mathrm{R}$ & $S$ & & + & \\
\hline
\end{tabular}

\footnotetext{
a Indicates that it was positive.
} 
Our results showed that 49 (40.9\%), 18 (15\%), 18 (15\%) and $17(14.2 \%)$ cases of the isolates were resistant to nalidixic acid, ciprofloxacin, norfloxacin, and ofloxacin, respectively. In the present study, the comparison of resistance patterns in ESBL-producing and -nonproducing E. coli demonstrated that the resistance of ESBL-producing bacteria is high and these results were similar to the study of Padmini and associates. We can explain that the plasmids carrying ESBLs genes may also transfer the genes resistant to non $\beta$-lactam antibiotics to the other bacteria (29). In this study, by using multiplex-PCR method, we examined the prevalence of qnr genes in strains of ESBL-producing E. coli and also the strains resistant to quinolones. As a result, the 10 strains (30.3\%) of ESBL-producing E. coli had qnr genes from which, 6 strains (18.2\%) possesd qnrB gene and 4 strains (12.1\%) had qnrS gene. In this study, of 14 positive isolates for qnr genes, 8(57.1\%), 9 (64.3\%), 8 (57.1\%), and $11(78.6 .1 \%)$ were resistant to Ciprofloxacin (CF), Ofloxacin (OF), Norfloxacin (NX) and Nalidixic acid (NA), respectively. Determinants of qnr can confer reduced susceptibility to fluoroquinolones or low-level quinolone resistance.

In 2007, for the first time in the Middle East, two studies were carried out on the prevalence rate of $q n r$ genes $(17,30)$. Oktem et al. in Turkey studied on 78 enterobacterial clinical isolates (including $34 \mathrm{E}$. coli and $44 \mathrm{Klebsi-}$ ella pneumonia), which all were ESBLs (+) and 5 isolates (6.3\%) were diagnosed to have qnrA gene. The qnrB and qnrS genes were not detected (30). Cattoir et al. in Kuwait examined 64 ESBL-producing enterobacterial isolates, including 29 E. coli, 19 K. pneumonia, 9 Proteus Mirabilis, 4 Enterobacter Cloacae, 3 Enterobacter aerogenes, 2 Citrobacter freundii, and 1 Serratia marcescens and could find only the qnrB gene just in 3 isolates (2 strains of E. Cloacae and 1 strain of $C$. frondy). In none of E. coli strains, qnrA, qnrB, and qnrS genes were found (17). In 2010, Bouchakour et al. studied on 39 enterobacterial isolates of ESBL-producing bacteria (including 16 E. coli, 14 Klebsiella spp, 8 E. Cloacae, and 1 P. Mirabilis) by multiplex-PCR technique in order to find $q n r$ genes. They found that in 14 isolates (36\%), there were qnr genes ( $q n r A: 10.25 \%$, qnrB: $23.07 \%$, and $q n r S: 2.56 \%$ ), which based on the type of bacteria, 3 strains (18.7\%) were from isolates of E. coli (1 qnrA, 1 qnrB and 1 qnrS), 5 strains (62.5\%) from isolates of E. Cloacae (4 qnrB and 1 qnrA), and 6 strains (50\%) from isolates of K. pneumonia (4 qnrB and 2 qnrA) (31).

In this study, the qnrS gene has been identified for the first time in Iran. Although because of the harmful side effects of quinolones in children, hospitals do not recommend these drugs for children, the prevalence of these genes was high in samples of this study. Probably, the high prevalence of $q n r$ genes in children is not related to the high use of quinolones; but may result from the transfer of these genes from adults or other sources. Also in this study, the prevalence rate of qnr genes in quinolone-resistant strains was also determined in 12 strains (26.1\%), which 5 strains (10.9\%) had qnrB gene and 7 strains (15.2\%) had qnrS gene. In 2003, Wang et al. by studying on
213 isolates (including 146 E. coli and 67K. pneumonia) resistant to ciprofloxacin (separated from pediatric ward of hospitals in Shanghai, China, by multiplex-PCR technique) found that $7.5 \%$ (4) of E. coli isolates and $11.9 \%$ (8) of $K$. pneumonia isolates contained qnr genes. Among these, the qnrA gene in 8 strains were resistant to ciprofloxacin (5.5\%), and qnrB as well as qnrS genes each in 5 strains (3.4\%) were resistant to ciprofloxacin (5). In this study, 26.1\% of E. coli strains resistant to quinolones had $q n r$ genes that in Wang study it was higher. This high prevalence can be due to non-promiscuous use of antibiotics in adults and horizontal transfer of the strains containing these genes to children.

In summary, our study showed that frequency of blaCTX-M was higher than bla-TEM and bla-SHV in ESBLs-producing E. coli, and also according to the similar studies in different places of the world, we can conclude that the prevalence rate of qnr genes is unfortunately very high in our country and more caution is required in prescribing and using antibiotics. We found a significant association between resistance to quinolones in ESBL-producing isolates and presence of qnr genes $(\mathrm{P}<0.05)$. Based on these results, using fluoroquinolones is not recommended in the children with complicated urinary tract infections because of ESBLs-producing E. coli and carbapenems can be used in these situations instead. Our data highlight the importance of detecting ESBLs, and qnr determinants in the area. The incidence of antimicrobial resistance genes such as ESBLs and qnr genes should also be monitored constantly.

\section{Acknowledgements}

The authors are grateful to Vice Chancellor for research of the Hamadan University of Medical Sciences, for providing financial support of this study.

\section{Funding/Supports}

This research was financially supported by Vice Chancellor for Research of Hamadan University of Medical Sciences.

\section{References}

1. Murray PR, Baron EJ, Jorgensen J. H., Landry ML, Michael A, Pfaller MA. Manual of Clinical Microbiology. 9th ed. American Society for Microbiology; 2007.

2. Piatti G, Mannini A, Balistreri M, Schito AM. Virulence factors in urinary Escherichia coli strains: phylogenetic background and quinolone and fluoroquinolone resistance. J Clin Microbiol. 2008;46(2):480-7.

3. White B. Diagnosis and treatment of urinary tract infections in children. Am Fam Physician. 2011;83(4):409-15.

4. Wang M, Tran JH, Jacoby GA, Zhang Y, Wang F, Hooper DC. Plasmid-mediated quinolone resistance in clinical isolates of Escherichia coli from Shanghai, China. Antimicrob Agents Chemother. 2003;47(7):2242-8.

5. Wang M, Sahm DF, Jacoby GA, Hooper DC. Emerging plasmidmediated quinolone resistance associated with the qnr gene in Klebsiella pneumoniae clinical isolates in the United States. Antimicrob Agents Chemother. 2004;48(4):1295-9. 
6. Jeong JY, Yoon HJ, Kim ES, Lee Y, Choi SH, Kim NJ, et al. Detection of qnr in clinical isolates of Escherichia coli from Korea. Antimicrob Agents Chemother. 2005;49(6):2522-4.

7. Schleiss MR. Principles of Antibacterial Therapy. In:Kliegman RM, editor. Nelson text book of pediatrics. 19th ed. Philadelphia: Elsevier; 2011.

8. Martinez-Martinez L, Pascual A, Jacoby GA. Quinolone resistance from a transferable plasmid. Lancet. 1998;351(9105):797-9.

9. Robicsek A, Jacoby GA, Hooper DC. The worldwide emergence of plasmid-mediated quinolone resistance. Lancet Infect Dis. 2006;6(10):629-40.

10. Strahilevitz J, Jacoby GA, Hooper DC, Robicsek A. Plasmid-mediated quinolone resistance: a multifaceted threat. Clin Microbiol Rev. 2009;22(4):664-89.

11. Khodursky AB, Zechiedrich EL, Cozzarelli NR. Topoisomerase IV is a target of quinolones in Escherichia coli. Proc Natl Acad Sci U S A. 1995;92(25):11801-5.

12. Tran JH, Jacoby GA, Hooper DC. Interaction of the plasmid-encoded quinolone resistance protein Qnr with Escherichia coli DNA gyrase. Antimicrob Agents Chemother. 2005;49(1):118-25.

13. Bauer AW, Kirby WM, Sherris JC, Turck M. Antibiotic susceptibility testing by a standardized single disk method. Am J Clin Pathol. 1966;45(4):493-6.

14. Clinical and Laboratory Standards Institute. Performance standards for antimicrobial susceptibility testing: seventeenth informational supplement. Wayne, PA: CLSI; 2007.

15. Kim HB, Park CH, Kim CJ, Kim EC, Jacoby GA, Hooper DC. Prevalence of plasmid-mediated quinolone resistance determinants over a 9-year period. Antimicrob Agents Chemother. 2009; 53(2):639-45.

16. Chroma M, Kolar M. Genetic methods for detection of antibiotic resistance: focus on extended-spectrum beta-lactamases. Biomed Pap Med Fac Univ Palacky Olomouc Czech Repub. 2010;154(4):289-96.

17. Cattoir V, Poirel L, Rotimi V, Soussy CJ, Nordmann P. Multiplex PCR for detection of plasmid-mediated quinolone resistance qnr genes in ESBL-producing enterobacterial isolates. J Antimicrob Chemother. 2007;60(2):394-7.

18. Datta P, Thakur A, Mishra B, Gupta V. Prevalence of clinical strains resistant to various beta-lactams in a tertiary care hospital in India. Jpn J Infect Dis. 2004;57(4):146-9.

19. Daoud Z, Hakime N. [Prevalence and susceptibility patterns of extended-spectrum betalactamase-producing Escherichia coli and Klebsiella pneumoniae in a general university hospital in Beirut, Lebanon]. Rev Esp Quimioter. 2003;16(2):233-8.

20. Shayanfar N, Rezaei M, Ahmadi M, Ehsanipour F. Evaluation of extended spectrum beta-lactamase (ESBL) positive strains of Kleb- siella pneumoniae and Escherichia coli in bacterial cultures. Iran JPathol. 2010;5:34-9.

21. Franiczek R, Dolna I, Krzyzanowska B, Szufnarowski K, KowalskaKrochmal B. Conjugative transfer of multiresistance plasmids from ESBL-positive Escherichia coli and Klebsiella spp. clinical isolates to Escherichia coli strain K12 C600. Adv Clin Exp Med. 2007;16(2):239-47.

22. Bali E, Acik, L., Sultan, N. Phenotypic and molecular characterization of SHV, TEM and CTX-M and extended spectrum beta -lactamase produced by Escherichia coli, Acinobacter baumanni and Klebsiella isolates in a Turkish hospital. Afr J Microbiol Res. 2010;4(8):650-4.

23. Sorlozano A, Gutierrez J, Fernandez F, Soto MJ, Piedrola G. A preliminary study on the presence of extended-spectrum beta-lactamases (ESBL) in clinical isolates of Escherichia coli in Granada (Spain). Ann Microbiol. 2004;54(2):99-104.

24. Park Y, Kang HK, Bae IK, Kim J, Kim JS, Uh Y, et al. Prevalence of the extended-spectrum beta-lactamase and qnr genes in clinical isolates of Escherichia coli. Korean J Lab Med. 2009;29(3):218-23.

25. Hussain M, Hasan F, Shah AA, Hameed A, Jung M, Rayamajhi N et al. Prevalence of class A and AmpC beta-lactamases in clinical Escherichia coli isolates from Pakistan Institute of Medical Science, Islamabad, Pakistan. Jpn J Infect Dis. 2011;64(3):249-52.

26. Yazdi M, Nazemi A, Miri Nargesi MS, Khatami Nejad MR. Prevallence of SHV/CTX-M/TEM beta lactamase resistance genes in Escherichia coli isolated from UTI in Tehran city. Iran J Pathol. 2010;4:48-54.

27. Rodriguez-Villalobos H, Malaviolle V, Frankard J, de Mendonca R, Nonhoff C, Struelens MJ. In vitro activity of temocillin against extended spectrum beta-lactamase-producing Escherichia coli. $J$ Antimicrob Chemother. 2006;57(4):771-4.

28. Bonnedahl J, Drobni M, Gauthier-Clerc M, Hernandez J, Granholm S, Kayser Y, et al. Dissemination of Escherichia coli with CTX-M type ESBL between humans and yellow-legged gulls in the south of France. PLoS One. 2009;4(6):e5958.

29. Padmini B, Appalaraju SB. Extended spectrum beta lactamases in urinary isolates of Escherichia coli and Klebsiella pneumonia prevalence and susceptibility pattern in a tertiary care hospital. Ind J Med Microbiol. 200 4;22(3):172-4.

30. Oktem IM, Gulay Z, Bicmen M, Gur D, Hitit Project Study Group. qnrA prevalence in extended-spectrum beta-lactamase-positive Enterobacteriaceae isolates from Turkey. Jpn J Infect Dis. 2008;61(1):13-7.

31. Bouchakour M, Zerouali K, Gros Claude JD, Amarouch H, El Mdaghri N, Courvalin P, et al. Plasmid-mediated quinolone resistance in expanded spectrum beta lactamase producing enterobacteriaceae in Morocco. J Infect Dev Ctries. 2010;4(12):779-803. 